\title{
Nature and Instigation of Medication Errors and Gazed Barriers in Reporting Them - A Prospective Observational Study
}

\author{
Vimali Murali, Durgaprasad Thamisetty, Prasanna Raju Yalvarthi \\ Department of Pharmacy Practice, Sri Padmavathi School of Pharmacy, Tirupati, Andhra Pradesh, INDIA
}

\begin{abstract}
Introduction: The goal of drug therapy is the improvement of a patient's health related quality of life while minimizing patient risk. But there are inherent risks associated with the therapeutic use of drugs and administration devices. Aim: Present study aims to identify and categorize MEs in the patients who were admitted in the General Medicine, Pediatrics and Surgery Departments in a tertiary care teaching hospital, Tirupati. The study also extended to find out the cause of MEs and the possible barriers for reporting the MEs. Methodology: A specially designed proforma was used for patient data collection \& the study was approved by institutional ethics committee. Inclusion criteria includes, patients who were hospitalized for more than three days and who were willing to give informed consent to participate in the study. Results: The prescriptions of the 100 patients included in the study were analyzed for medication errors and $52.7 \%$ of prescriptions were presented with medication errors. The persons involved in the medication errors include physician (prescriber), nurse (administrator) and the patients (consumer). The major causes of MEs were found to be excessive work load, lack of knowledge and non-compliance by the patients to the drugs. Conclusion: The establishment of a blame-free, non-punitive environment can promote ME reporting.
\end{abstract}

Key words: Medication Errors (ME), NCCMERP, HRQOL, Barriers of ME reporting, Clinical pharmacist, Patient care.

\section{INTRODUCTION}

NCC MERP defines medication error as "A medication error is any preventable event that may cause or lead to inappropriate medication use or patient harm while the medication is in the control of the health care professional, patient, or consumer. Such events may be related to professional practice, health care products, procedures, and systems, including prescribing, order communication, product labeling, packaging, and nomenclature, compounding, dispensing, distribution, administration, education, monitoring, and use. ${ }^{1,2}$

Medication errors can occur in any stages like choosing the drug, writing prescription, manufacturing, dispensing, administering and monitoring the drug therapy. 3,4
MEs account for one-sixth of all annual deaths in the United States. From 1983 to 1993 the numbers of deaths from medication errors and adverse reactions to medicines used in US hospitals increased from 2876 to 739115 and from 1990 to 2000 the annual number of deaths from medication errors in the UK increased from about 20 to just fewer than 200.16. According to a 2000 report citing UK medical defense organizations, $125 \%$ of all litigation claims in general medical practice were due to medication errors. ${ }^{5}$

\section{OBJECTIVE}

The main objective of this present study is to identify the medication errors, categorize them based on various classification systems of $\mathrm{ME}$, to detect the possible
DOI: 10.5530/ijopp.10.2.20

Address for correspondence: Dr. Vimali. $M$, Doctor of Pharmacy (Post Baccalaureate), Department of Pharmacy Practice, Sri Padmavathi School of Pharmacy, Tirupati, Andhra Pradesh, India. Phone no: +91 8825146606 E-mail: vimalimmc@gmail.com 
provocations of medication errors and identify the potential barriers of reporting them.

\section{Study design}

The present study was designed as cross sectional prospective observational study.

\section{Study population}

The study included 100 in-patients, prescribers, transcribers and nurses.

\section{Study place}

The study was conducted in 3 departments including General Medicine, Pediatrics and Surgery departments of a Tertiary Care Teaching Hospital, Tirupati.

\section{Study period}

The study was conducted for a period of three months from November 2015 to January 2016.

\section{Data collection}

A specially designed proforma was used to collect the data from the patient. The data were collected using patient medication profile review and from direct patient interview.

\section{Dosage forms}

The dosage forms included in this study were tablets, syrups, capsules, injections and infusions. The study has been conducted after approved by IEC and after getting informed consent form (both languages). Patients who were hospitalized more than 3 days and agreed to give informed consent were included in this study. Exclusion criteria include patients administering their own drugs and injections in the unannounced control visit.

\section{RESULTS}

A total of 100 patients were included in the study. Maximum number medication errors were observed in geriatric and pediatric patients (Figure 1). This may be due to incorrect dose calculation and lack of proper individualizing of dose in these patients (Table 1).

The patients were categorized based on the co-morbidities present to them. Maximum patients were found to have no co-morbidity (Figure 2).

The patients were categorized based on the number of drugs prescribed to them per prescription. Maximum number of patients was found to be prescribed with 4 to 6 drugs (Table 2).
Table 1: Department wise distribution of patients.

\begin{tabular}{cc}
\hline Department & No. of patients \\
\hline General surgery & 24 \\
Pediatrics & 29 \\
General medicine & 47
\end{tabular}

\section{Table 2: Number of drugs prescribed per patient.}

\begin{tabular}{cc} 
No. of drugs & No. of patients \\
\hline 1 to 3 & 8 \\
4 to 6 & 34 \\
7 to 9 & 28 \\
10 to 12 & 14 \\
13 to 15 & 11
\end{tabular}

\section{Table 3: Length of hospital stay of patients.}

\begin{tabular}{cc} 
Hospital stay & No. of patients \\
\hline less than 1 week & 76 \\
1 to 2 weeks & 15 \\
2 to 3 weeks & 4 \\
3 to 4 weeks & 2 \\
above 4 weeks & 3
\end{tabular}

\section{Table 4: Administering and dispensing errors}

\begin{tabular}{cc} 
Type of error & No. of errors \\
\hline Time of administration & 167 \\
Unordered drug & 31 \\
Omission of drug & 187 \\
Unordered dose & 9 \\
Wrong dose & 56 \\
Wrong administration technique & 38 \\
Wrong route & 41 \\
Drug formulation & 29
\end{tabular}

Table 5: Prescribing errors.

\begin{tabular}{cc}
\hline Type of error & No. of errors \\
\hline Drug name & 39 \\
Drug formulation & 29 \\
Omission of route & 112 \\
Omission of dose & 82 \\
Dosage regimen & 23 \\
Wrong administration technique & 12 \\
Wrong dose & 35 \\
Omission of drug & 67
\end{tabular}

Table 6: Medication errors based on departments.

\begin{tabular}{cc} 
Department & No. of errors \\
\hline General Surgery & 214 \\
Pediatrics & 137 \\
General medicine(Male) & 356 \\
General medicine(Female) & 341
\end{tabular}




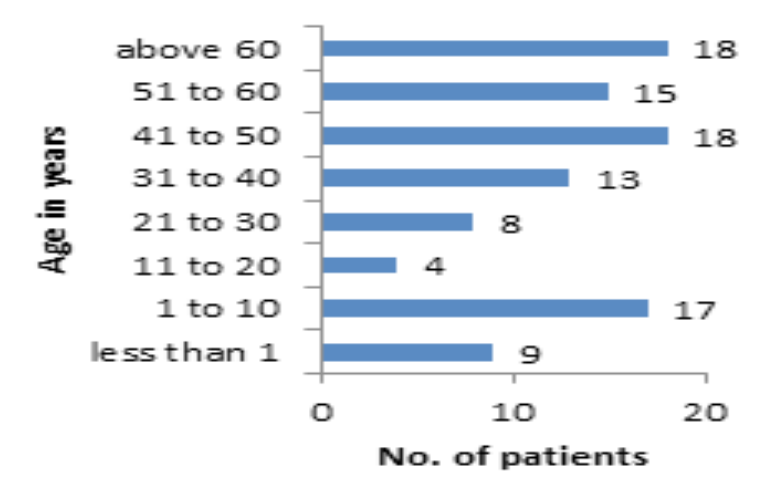

Figure 1: Age wise distribution of patients.

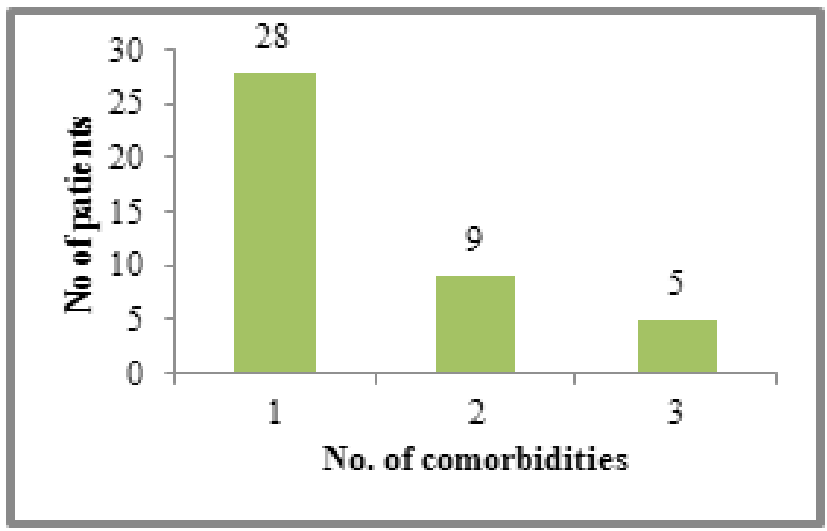

Figure 2: No. of patients based on co-morbidities.

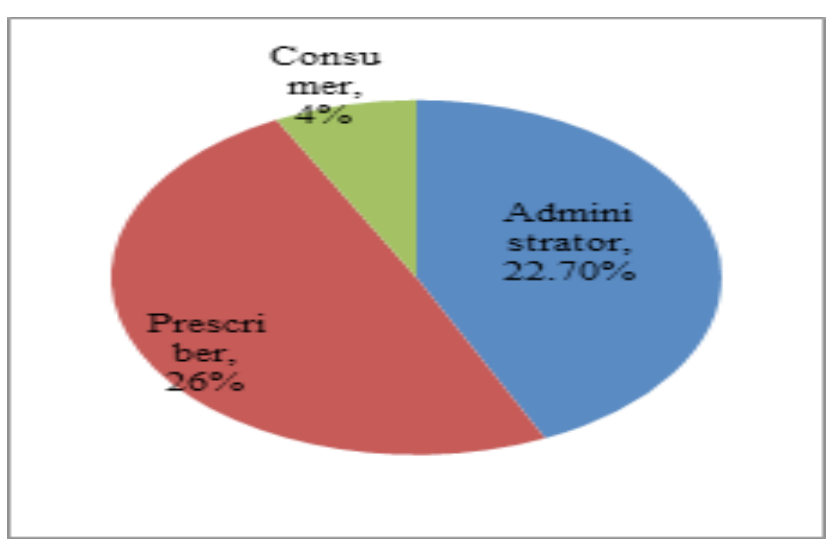

Figure 3: Medication errors based on persons involved.

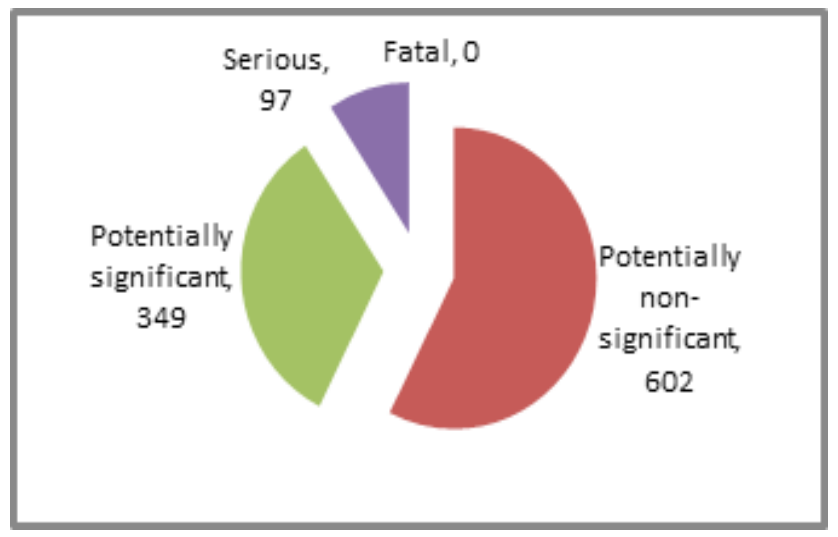

Figure 4: Medication errors based on potentiality.
Categorization based on the length of hospital stay of the patients is shown in Table 3.

The prescriptions of the 100 patients included in the study were analyzed for medication errors and $52.7 \%$ of prescriptions were presented with medication errors (Figure 3). The persons involved in the medication errors include physician (prescriber), nurse (administrator) and the patients (consumer).

The drugs were administered and dispensed to the patients by the nurses in the hospital. A total of 558 errors occurred while administering and dispensing the drugs to the patients. The various errors occurred while administering and dispensing the drugs are shown in Table 4.

Physician induced medication errors were found to be 399. The various types of prescribing errors are shown in Table 5.

The maximum number of medication errors occurred primarily in geriatric patients of various illnesses, admitted to the General Medicine department (Table 6). The main reasons for medication error in this department includes multiple drug therapy of the patients, more number of patients when compared to other departments and lesser number of healthcare professionals to serve them. Inexperienced student trainee nurses were allowed for administering and dispensing of drugs to the patients with less supervision of the chief and head nurses also paved way for the medication errors.

The medication errors based on their potentiality are shown in Figure 4.

Though majority of the medication errors were found to be potentially non-significant, 97 medication errors were serious and caused complications or permanent illness to the patients. Potentially significant medication errors were resulted in temporary harm or worsening of the illness of the patients.

\section{DISCUSSION}

Previous studies have suggested a need for a unified medication system to eliminate errors at the ordering and transcription stage. ${ }^{6} \mathrm{~A}$ study conducted by Johanna I. Westbrook at 2010 suggests the administering errors to the patient as $74.4 \%$. In this study, the administering and dispensing errors were found to be $53.24 \%$. Omission of the drug ranks top in the administering error, which is followed by wrong time of administration and wrong dose.

As stated by Bryony Dean, in his study conducted in $2002 .{ }^{8}$ prescribing errors affects $7 \%$ of medication orders, $2 \%$ of patient days and $50 \%$ of hospital

Indian Journal of Pharmacy Practice, Vol 10, Issue 2, Apr-Jun, 2017 
admissions. The prescribing errors in the present study were found to be $38.01 \%$. Omission of route in the prescription is the major prescribing errors noted. Omission of dose ranks second in the prescribing errors. Maximum of errors were noted in general medicine department, both male and female, followed by general surgery. Least medication errors were noted in the paediatrics department of the hospital. $^{9}$

As reported by Timothy in his study conducted in $1990,{ }^{10} 57.7 \%$ medication errors were found to be potentially significant. In this study, $33.3 \%$ medication errors were found to be potentially significant and $9 \%$ were found to be serious medication errors.

The causes of medication errors were found to be Excessive work load, depression and exhaustion, lack of knowledge, non-compliance by the patients to the drugs, working overtime with inadequate resources, poor support. The causes of non-reporting were found to be fear of disciplinary procedures. ${ }^{11,12}$

The reporting of errors, including near-misses, should be encouraged. Computerized prescribing systems, bar-coded medication systems, and cross-checking-to intercept such errors should be facilitated. Proper rules and Education to reduce the medication errors are to be done..$^{13,14}$ Medication chart should state the components -especially drug form and route. Using error reports to identify areas of likeliest occurrence and simplifying and standardizing the steps in the treatment process may be helpful. A ME reporting system should be readily accessible, with clear information on how to report a medication error, and reporting should be followed by feedback. ${ }^{15}$

This study was conducted only for three months, focusing majorly on the major departments of the hospital. More research, focusing on all the other departments, is needed in this field to reduce uncertainty and generate evidence based recommendations for physicians.

\section{CONCLUSION}

Better patient care is the prime motto for all healthcare professionals. The quality of patient care is determined by the quality of infrastructure, quality of training, competence of personnel and efficiency of operational systems. No patients should be harmed with medication errors. Medication errors can be preventable through effective comprehensive system involving clinical pharmacists, physicians, nurses and patients. Regulatory agencies like Cen- ter for Drug Evaluation and Research (CDER), the Division of Medication Error Prevention and Analysis (DMEPA) can improve methods for detecting and reporting the medication errors and thus the quality of patient care can also be improved.

\section{ACKNOWLEDGEMENT}

The authors acknowledge the support provided by the Government Hospital, Tirupati and the participants.

\section{CONFLICT OF INTEREST}

The authors declare no conflict of interest.

\section{ABBREVIATION USED}

ME: Medication Errors; NCCMERP: National Coordinating Council for Medication Error Reporting and Prevention; HRQOL: Health Related Quality of Life; IEC: Institutional Ethical Committee.

\section{REFERENCES}

1. National Coordinating Council for Medication Error Reporting and Prevention (NCC MERP). About Medication Errors. [Cited 17-04-16]. http://www.nccmerp. org/aboutmederrors.htm.

2. Aronson JK. Medication errors: definitions and classification. British Journal of Clinical Pharmacology. 2009;67(6):599-604.

3. Ferner RE, Aronson JK. Clarification of terminology in medication errors. Drug safety. 2006;29(11):1011-22.

4. Flynn EA, Barker KN, Carnahan BJ. National observational study of prescription dispensing accuracy and safety in 50 pharmacies. Journal of the American Pharmaceutical Association. 2003;43(2):191-200.

5. Lesar TS, Briceland L, Stein DS. Factors related to errors in medication prescribing. Jama. 1997;277(4):312-7.

6. Westbrook JI, Woods A, Rob MI, Dunsmuir WT, Day RO. Association of interruptions with an increased risk and severity of medication administration errors. Archives of Internal medicine. 2010;170(8):683-90.

7. Dean B, Schachter M, Vincent C, Barber N. Causes of prescribing errors in hospital inpatients: a prospective study. The Lancet. 2002;359(9315):1373-8.

8. Lewis PJ, Dornan T, Taylor D, Tully MP, Wass V, Ashcroft DM. Prevalence, incidence and nature of prescribing errors in hospital inpatients. Drug safety. 2009;32(5):379-89.

9. Lesar TS, Briceland LL, Delcoure K, Parmalee JC, Masta-Gornic V, Pohl H. Medication prescribing errors in a teaching hospital. Jama. 1990;263(17):232934.

10. Mehta S, Gogtay NJ. From the pen to the patient: Minimising medication errors. Journal of Postgraduate Medicine. 2005;51(1):3.

11. Lehmann DF, Page N, Kirschman K, Sedore A, Guharoy R, Medicis J, et al. Every error a treasure: improving medication use with a nonpunitive reporting system. The Joint Commission Journal on Quality and Patient Safety. 2007;33(7):401-7.

12. Handler SM, Perera S, Olshansky EF, Studenski SA, Nace DA, Fridsma $\mathrm{DB}$, et al. Identifying modifiable barriers to medication error reporting in the nursing home setting. Journal of the American Medical Directors Association. 2007;8(9):568-74.

13. Handler SM, Nace DA, Studenski SA, Fridsma DB. Medication error reporting in long term care. The American journal of geriatric pharmacotherapy. 2004;2(3):190-6.

14. Wilkins K, Shields M. Correlates of medication error in hospitals. Health reports. 2008;19(2):7-18. 